American Journal of Animal and Veterinary Sciences 3 (1): 32-35, 2008

ISSN 1557-4555

(C) 2008 Science Publications

\title{
Ultrasonographic Apperance of the Gestational Structures Throughout Pregnancy in Bitches
}

\author{
A. Aissi and C. Slimani \\ Department of Veterinary, Faculty of sciences, Batna University, Batna, Algeria
}

\begin{abstract}
Ultrasonographic examinations of 10 pregnant bitches with known breeding dates were made on successive days to establish the identifiable characteristics of pregnancy. Subsequent serial examinations were made to sonographically characterize normal canine prenatal development based about the first mating. The initial detection of the fetal and extra-fetal structures were as follows: gestational sac at day $17.88 \pm 1.13$ (16-21); zonary placenta in the uterine wall at day $23.70 \pm 0.78$ (23-

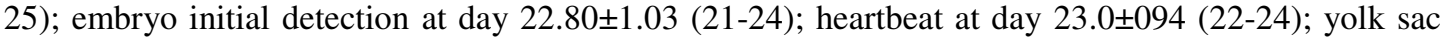
membrane at day $24.8 \pm 0.78$ (24-26); amniotic membrane at day $26.81 \pm 0.60$ (26-28); fetal movement at day $30.40 \pm 1.64$ (28-32); stomach at day 33.40 \pm 1.07 (32-35); urinary bladder at day $34.90 \pm 1.19$ (33$37)$; skeleton at day $35.10 \pm 073$ (34-36).
\end{abstract}

Key words: Bitch, ultrasound, pregnancy, fetal structures

\section{INTRODUCTION}

The early determination of pregnancy and the gestational age are important for reproductive management in small animal practices. In addition, predicting the parturition date can help in managing parturition or planning a Cesarean section in pregnant bitches with multiple mating or an unknown mating time $^{[7]}$. Ultrasonography is a useful imaging modality for determining pregnancy ${ }^{[4,5,8,15]}$, estimating the litter size $^{[5,8]}$, fetal development ${ }^{[9,13]}$ and uterine examination after parturition ${ }^{[2]}$, a reproductive examination and the direct detection of ovulation ${ }^{[12]}$. In veterinary medicine, estimation of the gestational age based on the anatomic appearance and predicting the parturition date by an ultrasonographic examination has been reported ${ }^{[1,7,13]}$. The aim of this study was to make an early determination of pregnancy, to establish the time for the initial detection of the extra-fetal and fetal structures using Ultrasonography and to provide the basic data for estimating the gestational age in bitches.

\section{MATERIALS AND METHODS}

Experimental animals: Ten bitches aged 2-4 years old, weighing 17-30 kg housed in surgery and imaging service, Batna University; all bitches were clinically healthy, without history of previous gynecological diseases. The pregnancy was detected using a transabdominal echography performed 15 days after the first mating with a SIEMENS Sonoline adara, Germen equipment and convex $5 \mathrm{MHz}$ transducer. The pregnancy was detected after visualization of gestation sacs and embryos and detection of cardiac function. Each dog was examined twice daily for any swelling of the vulva and the presence of a vaginal discharge, which signified the onset of proestrus. The bitches were mated if these signs were present. Serial ultrasonographic examinations were performed to make an early diagnosis of pregnancy and determine the time of the initial detection of the extra-fetal and fetal structures.

Ultrasonographic examination: Serial ultrasonographic examinations were performed every tow days from day 15 post mating. All the dogs were examined using realtime B-mode ultrasonography in dorsal recumbency. The gestational age at the time of the initial detection and the appearance of the following features of pregnancy were recorded: gestational sac, zonary placenta, feta membrane, embryo, heartbeat, limb buds, skeleton, fetal movement and abdominal viscera.

\section{RESULTS}

The Ultrasonography performed between 16 and 21 days after the first copulation, detected pregnancy in all bitches. During this period the uterine vesicle (gestation sac) appearance: a spherical anechoic cavity.

Corresponding Author: A. Aissi, Department of Veterinary, Faculty of sciences, Surgery and Imaging Services, Batna University, Batna 05000, Algeria Tel: 00.213.770.91.21.12 Fax: 00.213.33.82.45.54 
At this stage the embryo is no visible. The ultrasound monitoring of the embryo could be followed as from 22 days post mating.

The time of initial detection of extra-fetal structures: Table 1 and Fig. 1 show the time of the initial detection and presence of extra-fetal structures and Table 2 and Fig. 2 show the time of the initial detection and presence of fetal structures.

The gestational sac was first detected on day $17.88 \pm 1.13$ (range: 16-21), compared with the hyperechoic uterus (Fig. 1, Day 16). The echogenic inner layers (Fig. 1, Day 21) surrounding the gestational sac was developed into a zonary placenta. The yolk sac membrane was first detected as an echogenic U-shape fetal membrane (Fig. 1, Day 23). In the longitudinal plane on day $24.8 \pm 0.78$ (range 24-26). The amniotic membrane was detected on day $26.81 \pm 0.60$ (26-28), which encompassed the embryo (Fig. 1, Day 26).

The time of initial detection of fetal anatomy structures: On day 22.80 \pm 1.03 (21-24), the embryo Fig. 1, Day 21) was first detected as an oblong structure

Table 1: Mean and range of the gestational age at the first ultrasonographic detection of the extra-fetal structures

\begin{tabular}{llc}
\hline Pregnancy features & Mean \pm SD & Range \\
\hline Gestational sac & $17.88 \pm 1.13$ & $16-21$ \\
Zonary placenta & $23.70 \pm 0.78$ & $23-25$ \\
Fetal membranes & $24.80 \pm 0.78$ & $24-26$ \\
Amniotic membrane & $26.81 \pm 0.60$ & $26-28$ \\
\hline
\end{tabular}

Table 2: Mean and range of the gestational age at the first ultrasonographic detection of the fetal structures in bitches

\begin{tabular}{lll}
\hline $\begin{array}{l}\text { Pregnancy features } \\
\text { (Embryo and fetus) }\end{array}$ & Mean \pm SD & Range \\
\hline Initial detection & & \\
Embryo & $22.80 \pm 1.03$ & $21-24$ \\
Heartbeat & $23.00 \pm 0.94$ & $22-24$ \\
Limb bud & $29.70 \pm 0.82$ & $28-31$ \\
Fetal movement & $30.40 \pm 1.64$ & $28-31$ \\
Stomach & $33.40 \pm 1.07$ & $32-35$ \\
Gall bladder & $32.90 \pm 1.73$ & $31-35$ \\
Urinary bladder & $34.90 \pm 1.19$ & $33-37$ \\
Skeleton & $35.10 \pm 0.73$ & $34-36$ \\
Lung & $36.10 \pm 0.51$ & $35-37$ \\
Liver & $35.40 \pm 0.70$ & $35-37$ \\
\hline
\end{tabular}
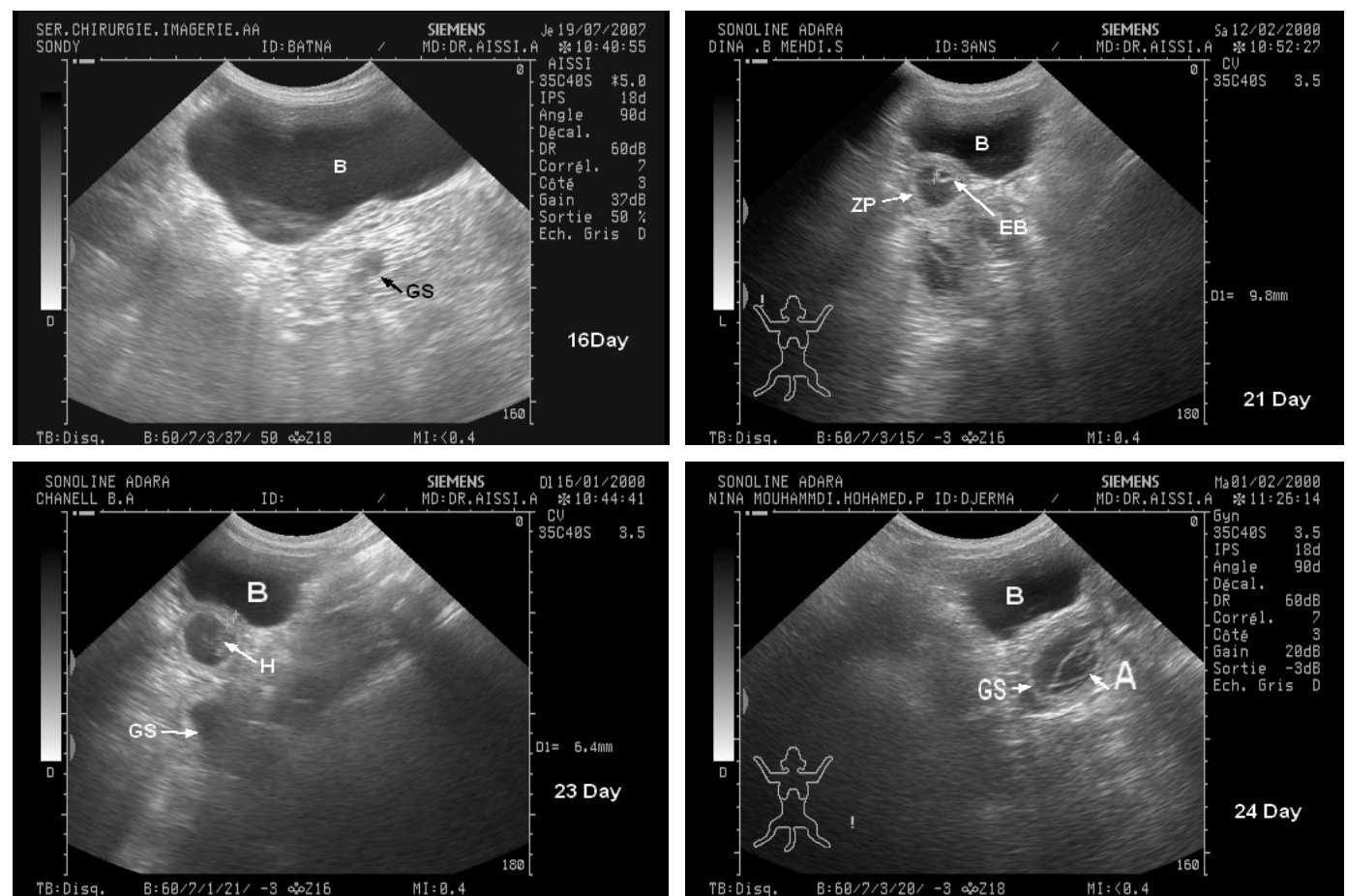

Fig. 1: Ultrasonograms of the extra-fetal structures in pregnant bitches. Day 16: Transverse image of the first detection of an gestational sac (GS: gestational sac). Day 21: Longitudinal image of the gestational sac. An echogenic inner placental layer was detected (ZP: zonary placenta) in the uterine wall (B: bladder, EB: embryo). Day 23: Longitudinal image of the gestational sac contained an embryo and heart (B: bladder, H: heart, GS: gestational sac).Day24 Longitudinal image of the gestational sac contained an embryo the tubular shape of the yolk sac membrane (A: amnios, B: bladder, GS: gestational sac) 

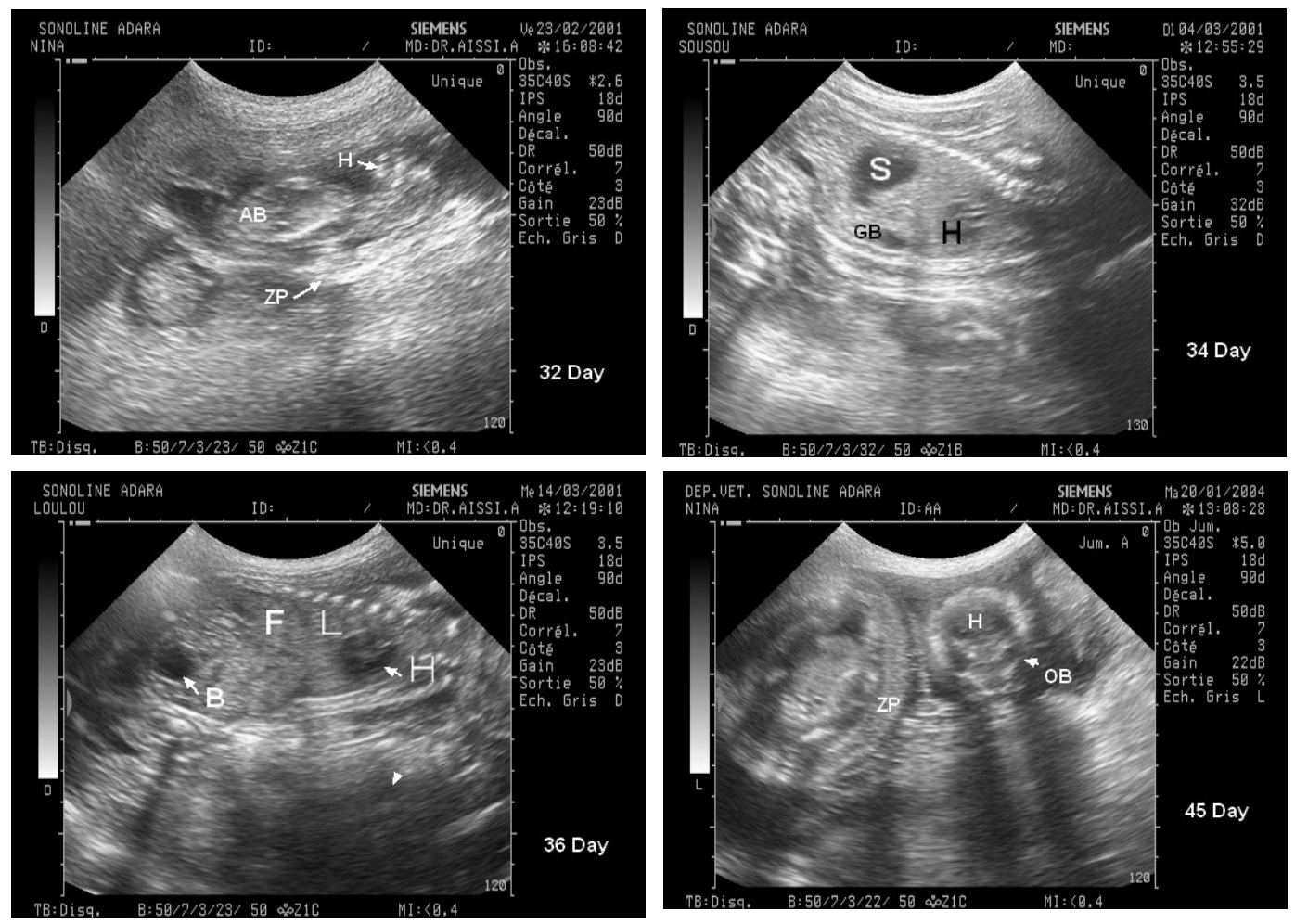

Fig. 2: Ultrasonograms of the fetal structures in pregnant bitches. Day 32: Longitudinal image of embryo (H: head, $\mathrm{AB}$, abdomen, $\mathrm{ZP}$ : zonary placenta). Day 34: Longitudinal image of a fetus with three anechoic area (H: heart, GB: gall bladder, S: stomach). Day 36: Longitudinal image of a fetus (B: bladder, F: liver, L: lung, H: heart). Day 45: image of a fetal head (H: head, OB: orbit, ZP: zonary placenta)

apposed the uterine wall. The heartbeat, which is one of

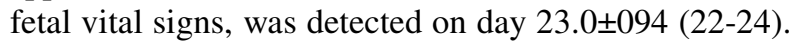
The limb buds were first detected on day $29.70 \pm 0.82$ (28-31) (Fig. 2 day 28) and fetal movement was detected on day $30.40 \pm 1.64$ (28-32). The first abdominal viscera detected were the stomach and urinary bladder on day $33.40 \pm 1.07$ (32-35) and 34.90 \pm 1.19 (33-37), respectively (Fig. 2 day 32-34-36).

The lung became hyperechoic, compared with the liver parenchyma, on day $35.10 \pm 073$ (range 34-36) (Fig. 2 day 36). At this time, the abdomen and thorax were distinct. The liver was observed to be hypoechoic, compared with the rest of the abdomen on day 36.10 \pm 051 (35-37) (Fig. 2 day 36). The skeleton (Fig. 2, Day 38) was detected as a hyperechoic structure on day $35.10 \pm 073$ (34-36).

\section{DISCUSSION}

In this present experiment study the detection of pregnancy in bitches observed an 16 and 21 days after the first copulation. Concannon et al. ${ }^{[3]}$ and Yeager ${ }^{[14]}$, indicate that the initial diagnosis of pregnancies bitches is possible at 19-20 days after the LH surge, also specify that this result is a discovery uterine vesicle between 13-21 days after the first mating, this study according the observations of Aissi et $a .^{[1]}$ on pregnancies bitches of various breeds in consultation submitted by the owner, a diagnosis of pregnancy is positive after 16 days of the first mating.

The uterine wall surrounding the gestational sac, an apparently hyperechoic inner layer was differentiated to the zonary placenta on day $23.70 \pm 0.78$ (23-25), which is similar to day 24-28 after ovulation ${ }^{[11]}$ and day 27-30 after the preovulatory LH surge ${ }^{[14]}$. The embryo and the heartbeat were first detected on day $22.80 \pm 1.03$ (21-24) and day $23.0 \pm 094$ (22-24), respectively. Days 21 to 26 and days 21 to 27 were characterized by the finding of an embryo and heartbeat, respectively $\mathrm{y}^{[6,11,10,14]}$. Yeager et al.$^{[14]}$ reported little anatomic differentiation within the embryo before day 30 . Before day 30 , the only distinguishable features of the bipolar embryo were the flickering motion of the heartbeat. In this study, embryo, heartbeat and limb bud were first detected before day 30 post mating. 
Most fetal anatomic structures were detected between days $30-50^{[14]}$. At this time, there was a similar time when the fetal structures were first detected (fetal movement, skeleton, stomach, urinary bladder) in the present and other studies ${ }^{[6,11,10,14]}$. For these reasons, the time the extra-fetal and fetal structures are first detected is useful for estimating the gestational age ${ }^{[1,2]}$.

\section{CONCLUSION}

The aim of this study was to make an early determination of pregnancy, to establish the time for the initial detection of fetal structures and anatomy development using ultrasonography and to provide the basic data for estimating the gestational age in bitches.

\section{REFERENCES}

1. Aissi, A. and C. Slimani, 2005. Suivi échographique de la gestation et datation de développement fœetal et embryonnaire chez la chienne. Congrès maghrébin, Alger Mai.

2. Boyd, J.S., J.P. Renton, M.J. Harvey, D.A. Nickson, P.D. Eckersall and J.M. Ferguson, 1993. Problems associated with ultrasonography of the canine ovary around the time of ovulation. J. Reprod. Fertil Suppl., 47: 101-105.

3. Concannon, P., T. Tsutsui and V. Shille, 2001. Embryo development, hormonal requirements and maternal responses during canine pregnancy. J. Reprod. Fertil Suppl., 57: 169-179.

4. England, G.C.W. and E.W. Allen, 1990. Studies on canine pregnancy using B-mode ultrasound: Diagnosis of early pregnancy and the number of conceptuses. J. Small Anim. Pract., 31: 321-323.

5. England, G.C.W. and D.J. Porter, 1990. Studies on canine pregnancy using B-mode ultrasound: development of the conceptus and determination of gestational age. J Small Anim. Pract., 31: 324-329.

6. Holst, P.A. and R.D. Phemister, 1974. Onset of diestrus in the beagle bitch: definition and significance. Am. J. Vet. Res., 35: 401-406.

7. Luvoni, G.C. and M. Beccaglia, 2006. The prediction of parturition date in canine pregnancy. Reprod. Domest. Anim., 41: 27-32.
8. Luvoni, G.C. and A. Grioni, 2000. Determination of gestational age in medium and small size bitches using ultrasonographic fetal measurements. J. Small Anim. Pract., 41: 292-294.

9. Moriyoshi, M., Y. Waki, T. Nakao and K. Kawata, 1996. Observation of the growth process of a beagle embryo and fetus by ultrasonography. J. Vet. Med. Sci., 58: 443-445.

10. Kang, B.K., H.S. Choi, C.H. Son, C.R. Shin, D.H. Seo and I.C. Park, 1997. Ultrasonographic apperance of the gestational structures throughout pregnancy in pet dogs. I. Time of initial detection of the fetal and extra-fetal structures. Korean J. Vet. Clin. Med., 14: 279-286.

11. Ko, J.S., B.S. Kim, S.A. Lee, Y.T. Cho, J.P. Kim, K.S. Oh, S.H. Kim, J.T. Kim, I.C. Park, Y.H. Kim and C.H. Son, 2004. Ultrasonographic apperance of the gestational structures throughout pregnancy in Shih-tzu bitches. I. Time of initial detection of the fetal and extra-fetal structures. Korean J. Vet. Clin., 21: 29-34.

12. Pharr, J.W. and K. Post, 1992. Ultrasonography and radiography of the canine postpartum uterus. Vet. Radiol. Ultrasound., 33: 35-40.

13. Son, C.H., K.A. Jeong, J.H. Kim, I.C. Park, S.H. Kim and C.S. Lee, 2001. Establishment of the prediction table of parturition day with ultrasonography in small pet dogs. J. Vet. Med. Sci., 63: 715-721.

14. Yeager, A.E., H.O. Mohammed, v. MeyersWallen, L. Vannerson and P.W. Concannon, 1992. Ultrasonographic appearance of the uterus, placenta, fetus and fetal membranes throughout accurately timed pregnancy in beagels. Am. J. Vet. Res., 53: 342-351.

15. Yeager, A.E. and P.W. Concannon, 1990. Association between the preovulatory LH surge and the early ultrasonographic detection of pregnancy and fetal heartbeats in beagle dogs. Theriogenology, 34: 655-665. 